\title{
Pengaruh Penambahan Tulangan Tekan Terhadap Momen Kapasitas Lentur dan Daktilitas Balok
}

\author{
Jaya Permana ${ }^{1}$, M. Muhtaris ${ }^{2}$, Eka Susanti*3 ${ }^{3}$ dan Yanisfa ${ }^{4}$ \\ 1,2,3,4 Institut Teknologi Adhi Tama Surabaya \\ Program Studi Teknik Sipil, FTSP-ITATS, Surabaya \\ e-mail:3ekasusanti2015@gmail.com, ${ }^{4}$ yanisfa.septi@gmail.com
}

Received 16 Agustus 2019; Reviewed 04 September 2019; Accepted 28 November 2019 Journal Homepage: http://jurnal.borneo.ac.id/index.php/borneoengineering

\begin{abstract}
Double reinforcement beam design, increasing the compressive reinforcement can increase the flexural capacity moment and ductility of concrete beams. This helps planners to improve flexural capacity moment with minimal dimensions, that are still acceptable in terms of aesthetics. The purpose of this study is to know how much influence the increasing compressive reinforcement can increase the flexural capacity moment and ductility of concrete beams. Experimental research with beam specimens $20 \times 20 \times 60 \mathrm{~cm}, 2 D 16$ tensile reinforcement, $f_{c}^{\prime} 25 \mathrm{mpa}$ and fy $320 \mathrm{mpa}$. With a ratio of compressive reinforcement to tensile reinforcement of 0.14; 0.25 and 0.59. Flexural strength testing uses flexible loading with a roll-pined joint. The process of load reading is yield phase until ultimate phase. The results of the analysis show an uses of increasing compressive reinforcement can increase the moment of flexural capacity and ductility. The addition of compressive reinforcement reached $25 \%$ from tensile reinforcement, can increase the moment of bending capacity by $4.47 \%$, but uses compressive reinforcement reached 50\% of tensile reinforcement, only increasing the bending moment capacity of $1.43 \%$. For ductility, uses compressive reinforcement reaches $25 \%$ from tensile reinforcement, can increase ductility by $19.73 \%$ and an increase of $26.17 \%$ by adding compressive reinforcement up to $50 \%$ of tensile reinforcement. From these results it appears that the more improvements added, the more the ductility increases and the less the moment the flexural capacity increases.
\end{abstract}

Keywords: Compressive Reinforcement, Flexural Capacity Moment, Ductility

\begin{abstract}
Abstrak
Pada disain balok dengan tulangan rangkap, peningkatan momen kapasitas lentur dan daktilitas balok beton bertulang dapat dilakukan dengan penambahan tulangan tekan. Hal ini membantu perencana dalam memaksimalkan kemampuan balok dengan dimensi yang minimal sehingga masih dapat diterima dari segi estetika. Penelitian ini bertujuan mengetahui seberapa besar pengaruh penambahan tulangan tekan terhadap peningkatan momen kapasitas lentur dan daktilitas. Penelitian ini bersifat eksperimental dengan benda uji balok berdimensi $20 \times 20 \times 60 \mathrm{~cm}$, tulangan tarik 2D16, mutu beton $\mathrm{fc} 25$ mpa dan mutu baja fy 320 mpa. Dengan rasio tulangan tekan terhadap tulangan tarik sebesar 0,14;0,25 dan 0,59. Pengujian kuat lentur menggunakan pembebanan satu bending dengan perletakan sendi-rol. Proses pembacaan dan pencataan dilakukan pada setiap fase yield sampai fase ultimate. Sehingga dapat diketahui besar pembebanan pada saat yield dan ultimate. Hasil analisis menunjukkan penambahan tulangan tekan dapat meningkatkan momen kapasitas lentur dan daktilitas. Penambahan tulangan tekan mencapai 25\% dr tulangan tarik, dapat meningkatkan momen kapasitas lentur sebesar 4,47\%, namun penambahan tulangan tekan hingga mencapai 50\% dr tulangan tarik, hanya meningkatkan kapasitas momen lentur sebesar 1,43\%. Untuk daktilitas, penambahan tulangan tekan mencapai $25 \%$ dr tulangan tarik, dapat meningkatkan daktilitas sebesar 19,73\% dan terjadi peningkatan 26,17\% dengan menambahkan tulangan tekan sampai 50\% dari tulangan tarik. Dari hasil tersebut terlihat semakin banyak tulangan tekan yang ditambahkan, semakin banyak peningkatan daktilitas dan semakin sedikit peningkatan momen kapasitas lenturnya .
\end{abstract}

Kata kunci: Tulangan Tekan, Momen Kapasitas Lentur, Daktilitas. 


\section{Pendahuluan}

Struktur beton bertulang merupakan gabungan dua bahan yang komposit, yaitu beton dan baja tulangan. Masing-masing bahan tersebut memiliki peranan tersendiri, yaitu beton yang kuat dalam menahan tekan dan baja tulangan yang kuat menahan tarik. Kedua material bekerja bersama-sama dalam menahan gaya yang bekerja. Disain tulangan lentur beton bertulang terdiri dari dua jenis penulangan yaitu: tulangan tunggal dan rangkap. Menurut Priestley, N (1990), Daktilitas material, dalam hal ini material baja dan material beton, dapat membantu dalam meningkatkan daktilitas elemen struktur balok beton bertulang. Dan menurut Park Paulay (1975), penggunaan tulangan rangkap dapat meningkatkan momen kapasitas lentur dan meningkatkan daktilitas pada balok. Hasil penelitiaan Oscar (2009) menyatakan bahwa hasil analisis dari permodelan benda uji dengan penambahan tulangan tekan, dapat meningkatkan daktilitas kurvatur.

Perubahan disain dilapangan terkadang menyebabkan perubahan pada kebutuhan akan kapasitas lentur balok yang lebih tinggi dari kapasitas disain. Dengan sifat penambahan tulangan tekan yang dapat peningkatan kapasitas lentur balok, maka hal ini akan dapat menjadi alternatif dalam mengatasi permasalahan tersebut, tanpa harus memperbesar ukuran balok dan memiliki nilai tambah dari segi estetika. Pada penelitian ini akan dilakukan studi eksperimental terhadap balok beton bertulang dengan variasi rasio tulangan tekan terhadap tulangan tarik, untuk melihat seberapa efektif baja tulangan SNI ( Standar Nasional Indonesia) mampu memberikan peningkatan momen kapasitas lentur dan daktilitas dalam kasus penambahan tulangan tekan.

\section{Metode Penelitian}

Penelitian ini bersifat eksperimental dengan data balok beton bertulang sebagai berikut:

Dimensi balok uji $\quad: 20 \times 20 \times 60 \mathrm{~cm}$

Mutu beton : $30 \mathrm{Mpa}$

Mutu baja : $\quad$ :320 Mpa

Dasar penetapan nilai rasio tulangan tarik dan penambahan tulangan tekan mengacu pada Park Paulay (1975) dan Nawy, E.G., (1996) untuk perkiraan analisis kuat lentur balok dengan tulangan rangkap. Pada penelitian ini digunakan tulangan tarik $2 \mathrm{D} 16\left(\mathrm{As}=401,92 \mathrm{~mm}^{2}\right)$ dan tulangan tekan 2D6 $\left(\right.$ As' $\left.=56,52 \mathrm{~mm}^{2}\right)$. Sehingga $\rho=A s / b d=401,92 /(200 * 166)=0,012 \approx 0,01$ dan $\frac{\rho^{\prime}}{\rho}=\frac{A s^{\prime}}{A s}=\frac{56,52}{401,92}=0,014 \approx 0$. Hal yang sama juga dilakukan untuk penambahan tulangan tekan berikutnya dan hasilnya dapat dilihat pada tabel 1 .

Tabel 1. Data benda uji

\begin{tabular}{lccc}
\hline Tipe & Jumlah tulangan tarik $(\boldsymbol{\rho})$ & Jumlah tulangan tekan ( $\left.\boldsymbol{\rho}^{\prime}\right)$ & $\boldsymbol{\rho}^{\prime} / \boldsymbol{\rho}$ \\
\hline BU1 & & 2D6 & 0,14 \\
BU2 & $2 \mathrm{D} 16$ & 2D8 & 0,25 \\
BU3 & & 3D10 & 0,59 \\
\hline
\end{tabular}

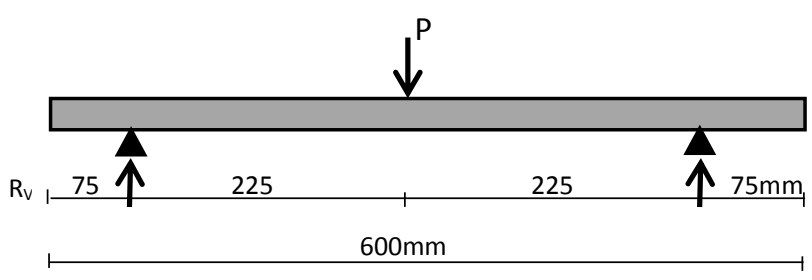

Gambar 1. Statika pembebanan lentur benda uji 
Masing-masing tipe benda uji dibuat 3 sample dan di uji lentur dengan meletakkan benda uji diantara dua tumpuan dan beban di tengah bentang. Hasil uji lentur berupa data beban ( P ) pada saat yield dan ultimit. Analisis momen kapasitas lentur dilakukan dengan analisis struktur statis tertentu, dimana balok terletak diantara 2 tumpuan dan beban $\mathrm{P}$ sesuai dengan data uji lentur dengan statika seperti pada gambar 1 .

$\mathbf{M}_{\max }$ ditengah bentang diperoleh dengan persamaan 1, dengan prosedur analisis daktilitas mengacu pada hasil penelitian Eka Susanti (2014) dan validasi persamaan pada buku Purwono, R (2002).

$$
\mathrm{M}_{\max }=\mathrm{R}_{\mathrm{vA}}(225+75)-(\mathrm{q}(0,5 \mathrm{~L}) \mathrm{x} 0,25 \mathrm{~L}
$$

Dimana:

$$
\begin{aligned}
& \mathrm{q} \quad=\text { berat sendiri balok }=\mathrm{b} \times \mathrm{h} \times \text { Bj balok } \\
& \mathrm{Bj} \text { balok }=2400 \mathrm{~kg} / \mathrm{m}^{3} \\
& \mathrm{R}_{\mathrm{VA}}=\mathrm{R}_{\mathrm{VB}}=\text { Reaksi perletakan }=\mathrm{P} / 2+\mathrm{qL} / 2
\end{aligned}
$$

Analisis dilanjutkan untuk memperoleh nilai kurvatur dan daktilitas balok. Perumusan berdasarkan diagram regangan dan tegangan balok seperti pada gambar 2 .
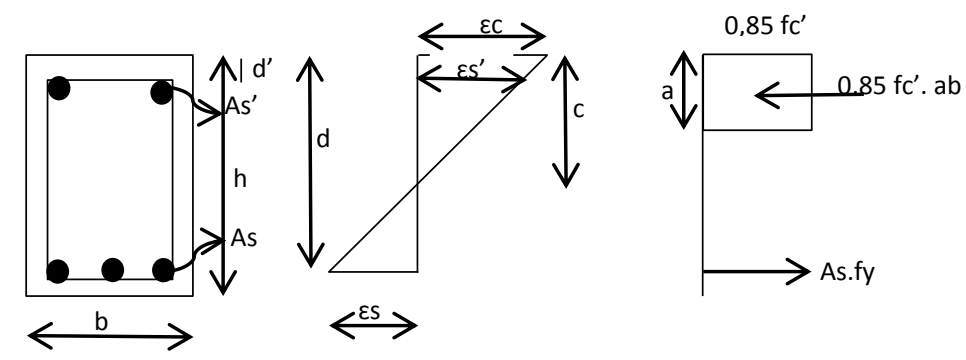

\section{Gambar. 2. Diagram Regangan dan Tegangan Beton Bertulang}

\subsection{Kurvatur Yield}

Nilai kurvatur pada saat yield dapat di hitung berdasarkan persamaan 2 sampai dengan 4, Priestly (1990).

$$
\begin{array}{r}
\left.c=\frac{M_{y}}{A_{s} f_{y}}\right) \\
\varepsilon_{c}=\frac{\varepsilon_{s y} c}{d-c}=\frac{\frac{f_{y}}{E_{s}} c}{d-c} \\
\varphi_{y}=\frac{\varepsilon_{c}}{c}
\end{array}
$$

Dimana:
$\mathrm{c} \quad=$ jarak garis netral $(\mathrm{cm})$
$\mathrm{d} \quad=$ Jarak permukaan sisi atas penampang ke titik berat tulangan tarik
My = Momen pada saat yield, diperoleh dari data uji beban lentur saat $\mathrm{P}$ mencapai yield dan My di hitung dengan persamaan 1
As = luas baja tulangan tarik $=n \frac{1}{4} \pi d^{2}\left(\mathrm{~cm}^{2}\right)$
$\mathrm{n}=$ Jumlah tulangan 
fy $=$ Mutu baja (Mpa)

Es $=$ Modulus elastisitas baja $=200.000 \mathrm{Mpa}$

$\varepsilon_{s y}=$ Regangan baja pada saat yield $=\frac{f_{y}}{E_{s}}$

$\varphi_{y}=$ Kurvatur pada saat yield

\subsection{Kurvatur Ultimit}

Nilai kurvatur pada saat ultimit dapat di hitung berdasarkan persamaan 5 sampai dengan 9, Priestly (1990).

$$
c=\left(\frac{a}{\beta}\right)
$$

Dimana: $\beta=0,85$ (untuk fc $\leq 30 \mathrm{Mpa}$ )

Tinggi daerah tekan beton, $a$ dicari dengan persamaan momen berikut (diasumsikan baja tekan belum leleh)

$$
M_{u}=0,85 f_{c}^{\prime} a b\left(d-\frac{a}{2}\right)+A_{s}{ }^{\prime} E_{s} \varepsilon_{c u}\left(\frac{a-\beta d^{\prime}}{a}\right)
$$

Cek apakah baja tekan sudah leleh, dengan persamaan 7 .

$$
\varepsilon_{s}^{\prime}=\frac{\varepsilon_{c u}\left(c-d^{\prime}\right)}{c}<\varepsilon_{s y}=\frac{f_{y}}{E_{s}}
$$

Apabila baja tekan belum leleh, maka nilai a yang dicari dengan persamaan 6 sudah benar. Namun apabila persamaan 7 menyatakan baja tekan sudah leleh, maka cara mencari nilai a diganti dengan menggunakan persamaan 8 :

$$
M_{u}=0,85 f_{c}^{\prime} a b\left(d-\frac{a}{2}\right)+A_{s}^{\prime} f_{y}\left(d-d^{\prime}\right)
$$

Berdasarkan nilai a ini, maka dapat dicari nilai c dengan persamaan 5 dan mencari kurvatur ultimit dengan persamaan 9 .

$$
\varphi_{u}=\frac{\varepsilon_{c u}}{c}
$$

Dimana:

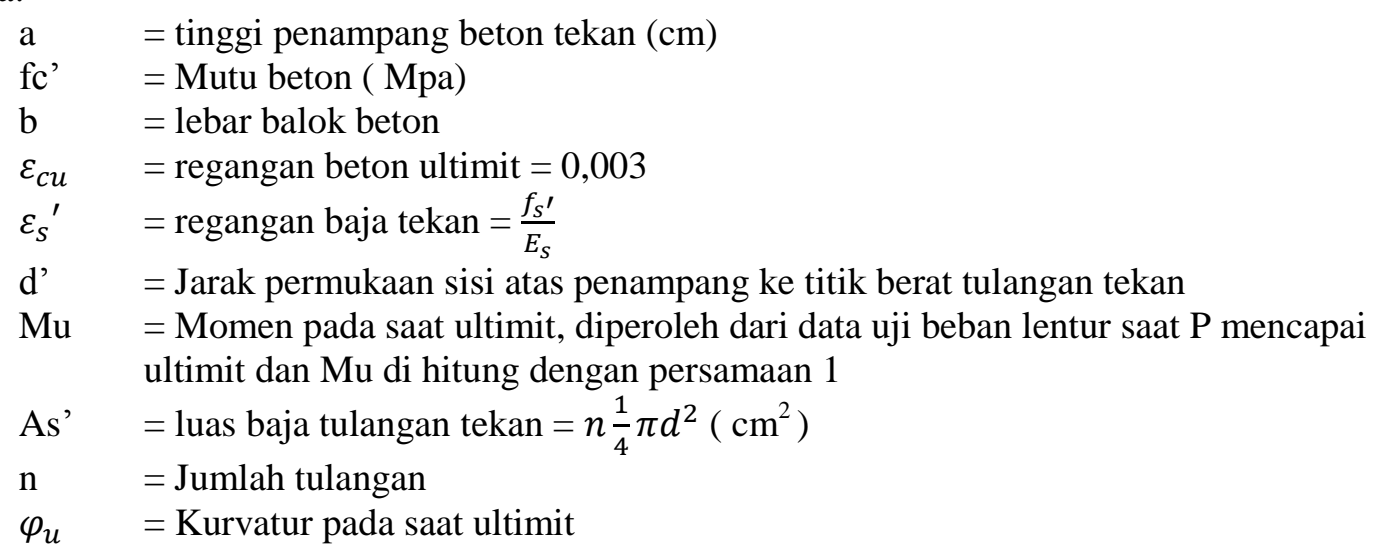




\subsection{Daktilitas $(\mu)$}

Daktilitas merupakan ukuran dari kinerja struktur terhadap beban gempa. Semakin daktail strukturnya, maka makin baik kinerja struktur tersebut dalam menerima beban gempa. Daktilitas ini adalah kemampuan struktur untuk masih tetap bertahan dari keadaan baja tulangan tarik sudah mencapai yield sampai beton mencapai keruntuhan/ultimit. Semakin lama kemampuan struktur tersebut bertahan dari keadaan yield hingga mencapai ultimit,makin daktail struktur tersebut dan semakin banyak nyawa akan terselamatkan. Daktilitas ini di hitung berdasarkan persamaan 10, Priestly (1990).

$$
\mu=\frac{\varphi_{u}}{\varphi_{y}}
$$

\section{Hasil dan Pembahasan}

Tabel 1. Hasil uji lentur dari 3 tipe benda uji adalah sebagai berikut

\begin{tabular}{lccccccccc}
\hline Tipe & \multicolumn{3}{c}{ BU1 (P dalam kg) } & \multicolumn{3}{c}{ BU2 (P dalam kg) } & \multicolumn{3}{c}{ BU3 (P dalam kg) } \\
\hline Benda & $\mathbf{1}$ & $\mathbf{2}$ & $\mathbf{3}$ & $\mathbf{1}$ & $\mathbf{2}$ & $\mathbf{3}$ & $\mathbf{1}$ & $\mathbf{2}$ & $\mathbf{3}$ \\
\hline & & & & & & & & & \\
& 500 & 500 & 500 & 500 & 500 & 500 & 500 & 500 & 500 \\
& 1000 & 1000 & 1000 & 1000 & 1000 & 1000 & 1000 & 1000 & 1000 \\
& 1500 & 1500 & 1500 & 1500 & 1500 & 1500 & 1500 & 1500 & 1500 \\
& 2000 & 2000 & 2000 & 2000 & 2000 & 2000 & 2000 & 2000 & 2000 \\
& 2500 & 2500 & 2500 & 2500 & 2500 & 2500 & 2500 & 2500 & 2500 \\
& 3000 & 3000 & 3000 & 3000 & 3000 & 3000 & 3000 & 3000 & 3000 \\
& 3500 & 3500 & 3500 & 3500 & 3500 & 3500 & 3500 & 3500 & 3500 \\
& 4000 & 4000 & 4000 & 4000 & 4000 & 4000 & 4000 & 4000 & 4000 \\
& 4500 & 4500 & 4500 & 4500 & 4500 & 4500 & 4500 & 4500 & 4500 \\
& 5000 & 5000 & 5000 & 5000 & 5000 & 5000 & 5000 & 5000 & 5000 \\
& 5500 & 5500 & 5500 & 5500 & 5500 & 5500 & 5500 & 5500 & 5500 \\
& 6000 & 6000 & 6000 & 6000 & 6000 & 6000 & 6000 & 6000 & 6000 \\
& 6500 & 6500 & 6500 & 6500 & 6500 & 6500 & 6500 & 6500 & 6500 \\
& 7000 & 7000 & 7000 & 7000 & 7000 & 7000 & 7000 & 7000 & 7000 \\
& 7500 & 7500 & 7500 & 7500 & 7500 & 7500 & 7500 & 7500 & 7500 \\
& 8000 & 8000 & 8000 & 8000 & 8000 & 8000 & 8000 & 8000 & 8000 \\
& 8500 & 8500 & 8500 & 8500 & 8500 & 8500 & 8500 & 8500 & 8500 \\
& 9000 & 9000 & 9000 & 9000 & 9000 & 9000 & 9000 & 9000 & 9000 \\
& 9500 & 9500 & 9500 & 9500 & 9500 & 9500 & 9500 & 9500 & 9500 \\
& 10000 & 10000 & 10000 & 10000 & 10000 & 10000 & 10000 & 10000 & 10000 \\
& 10500 & 10500 & 10500 & 10500 & 10500 & 10500 & 10500 & 10500 & 10500 \\
& 11000 & 11000 & 11000 & 11000 & 11000 & 11000 & 11000 & 11000 \\
& 11500 & & 11500 & 11500 & 11500 & 11500 & 11500 & 11500 \\
& 12000 & & & 12000 & & & 12000 & 12000 \\
\hline
\end{tabular}

Data hasil uji lentur di rangkum dalam tabel 2 untuk kemudahan perhitungan.

Tabel 2. Hasil uji lentur rata-rata

\begin{tabular}{ccc}
\hline Tipe & $* \mathbf{P}(\mathbf{k g})$ saat yield & $* \mathbf{P}(\mathbf{k g})$ saat ultimit \\
\hline BU1 & 7.000 & $11.166,67$ \\
BU2 & $5.333,3$ & $11.666,67$ \\
BU3 & $1.666,67$ & $11.833,33$ \\
\hline
\end{tabular}

*P adalah nilai rata-rata dari ke tiga benda uji untuk satu tipe benda uji. 
Berdasarkan tabel 2 dan persamaan 1 sampai dengan persamaan 10 maka dilakukan analisis momen kapasitas lentur, kurvatur dan daktilitas seperti contoh berikut.

Contoh analisis momen kapasitas lentur, kurvatur dan daktilitas untuk balok tipe BU1:

\section{a. Fase Yield}

Nilai P rata-rata pada fase yield dari ketiga benda uji adalah:

$P_{\text {yield }}=\frac{5500+8000+7500}{3}=7000 \mathrm{~kg}=70000 \mathrm{~N}$

Berat balok beton (q)

$q=B j_{\text {Beton }} \times b \times h=0,000024 \times 200 \times 200=0,96 \mathrm{~N} / \mathrm{mm}$

Reaksi perletakan:

$$
\begin{aligned}
R V A= & \frac{P_{\text {yield }}}{2}+Q \frac{L}{2} \\
& =\frac{70000}{2}+0,96 \times \frac{600}{2}=35288 \mathrm{~N}
\end{aligned}
$$

Momen yield yang terjadi adalah:

$$
\begin{aligned}
M_{y} & =R v a \cdot \frac{L o}{2}-\frac{Q}{2}\left(\frac{L}{2}\right)^{2} \\
& =35288 \times \frac{450}{2}-\frac{0,96}{2}\left(\frac{600}{2}\right)^{2}=10543200 \mathrm{Nmm}
\end{aligned}
$$

Tinggi daerah tekan beton ( $\mathrm{c}$ ):

$c=\frac{M_{y}}{A_{s} \cdot f_{y}}=\frac{10543200}{401,92 \times 320}=81,975 \mathrm{~mm}$

Regangan beton pada saat baja tulangan tariksudah mencapai fase yield

$\varepsilon_{c}=\frac{\varepsilon_{y} \cdot c}{d-c}=\frac{0,0016 \times 81,975}{171-81,975}=0,00147$

Kurvatur pada fase yield:

$\varphi_{y}=\frac{\varepsilon_{c}}{c}=\frac{0,00147}{81,975}=0,00001797 \mathrm{Rad} / \mathrm{mm}$

\section{b. Fase Ultimate}

Nilai P rata-rata pada fase ultimit dari ketiga benda uji adalah:

$$
P_{\text {ultimte }}=\frac{10500+11000+12000}{3}=11666,66 \mathrm{~kg}=116666,6 \mathrm{~N}
$$

Reaksi perletakan: 
$R v a=\frac{P_{u l t m}}{2}+Q \frac{L}{2}=\frac{116666,6}{2}+0,96 \frac{600}{2}=56121,3 \mathrm{~N}$

Momen ultimit yang terjadi adalah:

$$
\begin{aligned}
M_{u} & =\operatorname{Rva} \cdot \frac{L o}{2}-\frac{Q}{2}\left(\frac{L}{2}\right)^{2} \\
& =56121,3 \times \frac{450}{2}-\frac{0,96}{2}\left(\frac{600}{2}\right)^{2}=16793200 \mathrm{Nmm}
\end{aligned}
$$

Untuk mencari tinggi daerah tekan beton (a), diasumsikan baja tekan belum leleh, maka:

$M_{u}=0,85 f c^{\prime} a b\left(d-\frac{a}{2}\right)+A_{s} E_{s} \varepsilon_{c}\left(\frac{a-\beta d^{\prime}}{a}\right)$

$16793200=0,85 \times 25 \times a \times 200\left(171-\frac{a}{2}\right)+401,92 \times 200000 \times 0,003\left(\frac{a-0,85 \times 20}{a}\right)$

$a=18,965 \mathrm{~mm}$

Tinggi daerah tekan beton:

$c=\frac{a}{\beta}=\frac{18,965}{0,85}=22,31 \mathrm{~mm}$

Cek apakah benar asumsi baja tekan belum leleh:

$\varepsilon_{s}^{\prime}=\frac{\varepsilon_{c u}\left(c-d^{\prime}\right)}{c}$

$=\frac{0,003(22,31-20)}{22,31}=0,0003108<\varepsilon_{s y}=0,0016$

Berarti benar baja tekan belum leleh.

Kurvatur ultimit:

$\varphi_{u}=\frac{\varepsilon_{c}}{c}=\frac{0,003}{22,31}=0,00013 \mathrm{Rad} / \mathrm{mm}$

Nilai daktilitas

Daktilitas $=\frac{\varphi_{u}}{\varphi_{y}}=\frac{0,00013}{0,00001797}=7,48$

Dengan cara yang sama, dilakukan analisis momen kapasitas lentur, kurvatur dan daktilitas untuk balok tipe BU2 dan BU3 yang hasilnya dapar dilihat pada tabel 4.

Tabel 3. Hasil analisis Momen, kurvatur dan daktilitas

\begin{tabular}{llrrllc}
\hline Tipe & $\boldsymbol{\rho} / \boldsymbol{\rho}$ & $\mathbf{M y}(\mathbf{N m m})$ & $\mathbf{M u}(\mathbf{N m m})$ & \multicolumn{1}{c}{$\boldsymbol{\varphi}_{\boldsymbol{y}}$} & \multicolumn{1}{c}{$\boldsymbol{\varphi}_{\boldsymbol{u}}$} & $\boldsymbol{\mu}$ \\
\hline BU1 & 0,14 & 10.543 .200 & 16.793 .200 & 0,00001797 & 0,00013 & 7,23 \\
BU2 & 0,25 & 8.021 .600 & 17.521 .600 & 0,00001473 & 0,000132 & 8,96 \\
BU3 & 0,59 & 2.521 .600 & 17.771 .600 & 0,000011633 & 0,000132 & 11,35 \\
\hline
\end{tabular}

Sebagai validasi hasil penelitian, hasil penelitian ini dapat dibandingakn dengan hasil penelitian terdahulu: 


\section{Perbandingan Terhadap Hasil Penelitian Oscar (2009)}

Tabel 2 Oscar (penelitian permodelan) menyatakan bahwa untuk balok R3-4 dengan rasio tulangan tarik $\rho=0,0125$ dan penambahan tulangan tekan mencapai $1 / 4$ tulangan tarik $\left(\frac{\rho^{\prime}}{\rho}=0,25\right)$, dapat mencapai daktilitas sebesar 9,8793 .

Tabel 3 pada penelitian ini (penelitian eksperimental), benda uji R3-4 sebanding dengan benda uji BU2, dengan nilai $\rho=0,012$ dan $\frac{\rho^{\prime}}{\rho}=0,25$ dan daktilitas yang dihasilkan adalah 8,96 . Apabila dibandingkan, terdapat selisih nilai penelitian permodelan terhadap nilai penelitian eksperimental sebesar $9,3 \%$.

\section{Perbandingan Terhadap Hasil Penelitian Park Paulay (1975)}

Keduanya merupakan hasil penelitian eksperimental dengan perbedaan karakteristik material baja dari negara masing-masing. Untuk memudahkan perbandingan hasil penelitian, maka tabel 3 diubah dalam bentuk prosentase peningkatan momen kapasitas lentur dan daktilitas, yang tertera pada tabel 4.

Tabel 4. Prosentase peningkatan momen kapasitas lentur dan daktilitas

\begin{tabular}{cll}
\hline $\begin{array}{c}\text { Peningkatan } \\
\boldsymbol{\rho} / \boldsymbol{\rho}\end{array}$ & $\begin{array}{l}\text { Peningkatan } \\
\text { Mu }(\boldsymbol{\%})\end{array}$ & $\begin{array}{l}\text { Peningkatan } \\
\boldsymbol{\mu}(\boldsymbol{\%})\end{array}$ \\
\hline $0,14 \operatorname{sd} 0,25$ & 4,47 & 19,73 \\
0,25 sd 0,59 & 1,43 & 26,17 \\
\hline
\end{tabular}

Dari tabel 4, terlihat bahwa penambahan tulangan tekan sampai dengan $25 \%$ dapat meningkatkan momen kapasitas lentur Mu mencapai 4,47\% dan daktilitas 19,73\%. Namun penambahan tulangan tekan diatas $25 \%$ sd $50 \%$, hanya meningkatkan sedikit kapasitas lentur dan banyak peningkatan nilai daktilitas.Dengan kata lain, penambahan tulangan tekan diatas 50\%, tdk efektif dalam peningkatan kapasitas lentur, namun sangat efektif dalam peningkatan daktilitas. Apabila dibandingkan terhadap hasil penelitian Park Paulay (1975), tabel 5, terdapat perbedaan yang sangat jauh. Penambahan tulangan tekan sampai dengan 30\%, dapat meningkatkan kapasitas lentur hingga $10 \%, 50 \%$ lebih tinggi dari hasil penelitian ini. Peningkatan daktilitas dengan penambahan tulangan tekan hingga $60 \%$ adalah 70 , lebih tinggi $63 \%$ dari hasil penelitian ini.

Tabel 5. Hasil penelitian Park Paulay (Prosentase peningkatan momen kapasitas lentur dan daktilitas)

\begin{tabular}{cll}
\hline $\begin{array}{c}\text { Peninglkatan } \\
\boldsymbol{\rho} / \boldsymbol{\rho}\end{array}$ & $\begin{array}{l}\text { Peningkatan } \\
\mathrm{Mu}(\%)\end{array}$ & $\begin{array}{l}\text { Peningkatan } \\
\mu(\%)\end{array}$ \\
\hline 0 sd 0,333 & 10 & 60 \\
0,333 sd 0,666 & 5 & 70 \\
\hline
\end{tabular}

Mengacu pada hasil penelitian Park Paulay ini, perlu adanya pembahasan lebih lanjut, mengenai hubungan daktilitas material baja terhadap peningkatan momen kapasitas lentur dan daktilitas balok beton bertulang. Perlu penambahan pada bahasan hasil uji tarik baja tulangan yang digunakan oleh Park Paulay terhadap hasil uji tarik baja tulangan SNI hasil produksi beberapa produsen baja Indonesia. Dengan penambahan bahasan tersebut, akan diperoleh analisis yang lebih dalam mengenai perbedaan hasil pengujian tersebut.

\section{Kesimpulan}

1. Penambahan tulangan tekan dapat meningkatkan momen kapasitas lentur dan daktilitas.

2. Namun semakin banyak tulangan tekan yang ditambahkan, momen kapasitas lentur hanya bertambah sedikit. Hal ini terlihat pada penambahan tulangan tekan hingga mencapai 50\% tulangan tarik, hanya meningkatkan kapasitas momen lentur sebesar 1,43\%. 
3. Namun yang terpenting adalah daktilitas struktur dapat terus meningkat dengan signifikan

4. Hasil penelitian berbeda jauh dengan hasil penelitian Park Paulay.

\section{Daftar Pustaka}

Eka Susanti (2014). Studi Perbandingan Nilai Kuat Lentur dan Daktilitas Beton Yang Menggunakan Pasir Merapi dan Pasir Lumajang, Jurnal KERN UPN, vol.4 No.1 hal 11-19, ISSN: 2087-7498

Nawy, E.G., (1996), "Reinforced Concrete, Fundamental Approach", 3rd ed, Prentice-Hall Inc.,New York.

Oscar Fithrah Nur (2009), Analisa Pengaruh Penambahan Tulangan Tekan TerhadapDdaktilitasKkurvatur Balok Beton Bertulang, Jurnal Rekayasa Sipil VOLUME 5 NO. 1, Pebruari 2009 ,ISSN1858-2133

Priestley, M.J.N.; dan Paulay, T (1990), Seismic Design of Reinforced Concrete and Masonry Building, John Wiley \& Sons.

Park, R.; dan Paulay, T (1975), Reinforced Concrete Structures, John Wiley \& Sons, 761 hal.

Purwono, R.; Tavio, Imran, I.; dan Raka I G. P (2002), Tata Cara Perhitungan Struktur Beton untuk Bangunan Gedung (SNI 03-2847-2002) Dilengkapi Penjelasan (S-2002), ITS Press, Surabaya, Indonesia, 408 hal 
